\title{
Keseragaman Bobot Resep Racikan Serbuk Bagi (Pulveres) Di Apotek Kota Bandar Lampung Tahun 2017
}

\author{
Pudji Rahayu ${ }^{1}$, Yusrizal ${ }^{2}$ \\ ${ }^{1}$ Jurusan Farmasi Politeknik Kesehatan Tanjungkarang \\ ${ }^{2}$ Jurusan Analis Kesehatan Politeknik Kesehatan Tanjungkarang
}

\begin{abstract}
Abstrak
Serbuk terbagi (pulveres) adalah serbuk yang dibagi dalam bobot yang kurang lebih sama yang dibungkus menggunakan bahan pembungkus yang cocok dan digunakan untuk sekali minum (dosis tunggal). Bahan pembungkus yang digunakan dapat berupa kertas perkamen atau kapsul disesuaikan dgn usia dan kondisi pasien. Salah satu syarat serbuk bagi (pulveres) yang baik yaitu harus memenuhi persyaratan keseragaman bobot. Faktor pelaksana dan penguasaan terhadap teknik peracikan khususnya pembuatan serbuk bagi akan menyebabkan variasi bobot dan kandungan. Variasi yang terlalu lebar akan menyebabkan dosis terlalu rendah atau terlalu tinggi dari permintaan penulis resep. Tujuan penelitian untuk mengetahui gambaran keseragaman bobot dan keseragaman kandungan parasetamol dalam resep sediaan serbuk bagi (pulveres) bungkus di apotek Kota Bandar Lampung dibandingkan persyaratan pada Farmakope Indonesia. Jenis penelitian deskriftif dengan desain Cross sectional. Kegiatan penelitian diawali penebusan resep dokter di apotek kemudian melakukan penimbangan dan menghitung keseragaman bobot. Analisa data menggunakan persentase, data disajikan dalam bentuk diagram. Hasil penelitian menunjukkan 95,24\% sediaan serbuk tidak memenuhi keseragaman bobot. Sesuai dengan keseragaman bobot sediaan dengan berat 150-300 mg maka tidak boleh satupun sediaan mempunyai berat menyimpang $15 \%$ dari bobot rata-rata sediaan.
\end{abstract}

Kata kunci: Keseragaman bobot, racikan,, serbuk bagi (pulveres)

\section{Diversity Weight Reception Making Powder For Pulveres At Pharmacy In The Bandar Lampung City 2017}

\begin{abstract}
Pulveres are powders which are divided into approximately equal weights which are wrapped using suitable packaging materials and used for one drink (single dose). The wrapping material used can be parchment paper or capsules adjusted to the age and condition of the patient. One of the requirements for a good powder (pulveres) is that it must meet the uniformity of weights. Executing factors and mastery of compounding techniques, especially for making powder will cause variations in weight and content. Variations that are too wide will cause the dose to be too low or too high from the request of the prescription. The purpose of this study was to determine the weight uniformity and uniformity of the content of paracetamol in the recipe of packaged pulveres at the pharmacy in Bandar Lampung City compared to the requirements of the Indonesian Pharmacopoeia. This research is descriptive with cross sectional design. The research activity was initiated by the doctor's redemption at the pharmacy and then weighing and calculating weight uniformity. Analysis of data using percentages, data is presented in the form of diagrams. The results showed $95.24 \%$ powder preparations did not meet the uniformity of weights. In accordance with the uniformity of the weight of the preparations with a weight of 150-300 mg, none of the preparations should have a weight deviating $15 \%$ from the average weight of the preparations.
\end{abstract}

Keywords: Uniformity of weights, concoctions ,, pulverizer

Korespondensi : Pudji Rahayu, Jurusan Farmasi Politeknik Kesehatan Tanjungkarang, Jalan Soekarno Hatta No.1 Bandar Lampung, Mobile Phone : 08127958850,e-mail: pudji_rahayu_yayuk@yahoo.com 


\section{Pendahuluan}

Sediaan farmasi adalah obat, bahan obat, obat tradisional, dan kosmetika (UU Kesehatan Republik Indonesia No. 36 Tahun 2009 Pasal 1). Bentuk-bentuk sediaan farmasi adalah sediaan padat, semipadat, dan cair. Salah satu jenis sediaan padat yang sering diresepkan untuk anak dan bayi adalah pulvis atau serbuk. Serbuk adalah campuran kering bahan obat atau zat kimia yang dihaluskan untuk pemakaian oral atau untuk pemakaian luar. Serbuk oral dapat diberikan dalam bentuk terbagi (pulveres) atau tidak terbagi (pulvis) (Syamsuni, 2007).

Serbuk terbagi (pulveres) adalah serbuk yang dibagi dalam bobot yang lebih kurang sama, dibungkus dengan kertas perkamen atau bahan pengemas lain yang cocok (Anief, 2008). Kelebihan dari bentuk serbuk bagi yaitu serbuk mempunyai luas permukaan yang lebih luas sehingga lebih mudah terdispersi dan lebih larut daripada sediaan yang dipadatkan. Serbuk juga lebih mudah digunakan untuk anak-anak atau orang tua yang sukar menelan tablet atau kapsul,. tetapi serbuk juga memiliki kekurangan yaitu tidak tertutupnya rasa dan bau yang tidak enak dan pada penyimpanan terkadang menjadi lembab atau basah (Syamsuni, 2007). Sediaan serbuk terbagi (pulveres) yang baik harus memenuhi syarat yaitu homogen, kering, mempunyai derajat kehalusan tertentu serta harus memenuhi persyaratan meliputi keseragaman bobot dan keseragaman kandungan atau dosis (Syamsuni, 2007).

Resep racikan serbuk bagi (pulveres) selain dikemas dengan kertas, bisa juga dikemas dalam kapsul. Bentuk kapsul sering diberikan pada pasien anak yang sudah mampu menelan kapsul. Kelebihan pemberian bentuk kapsul ini selain dapat mengurangi rasa pahit obat juga sediaan lebih stabil dalam penyimpanan. Meskipun sediaan ini memiliki syarat untuk keseragaman bobot dan kandungan, tidak jarang ditemukannya kasus yang menyimpang dari hal ini.

Peresepan obat racikan puyer juga meningkatkan kecenderungan penggunaan obat irasional, karena penggunaan obat polifarmasi yang tidak mudah diketahui oleh pasien. Selain itu, dari segi keamanan dosis banyak pihak yang meragukan apakah dosis yang diberikan dalam sediaan puyer sesuai atau tidak. Hal ini dilihat karena sebagian besar pembagian dosis yang dibuat dalam bungkus-bungkus kecil dari puyer hanya dibagi berdasarkan visual saja tanpa ditimbang (Hasan Amirul, 2009).
Hasil penelitan yang telah dilakukan Lalu Syarif Hidayahtullah tahun 2009 tentang uji keseragaman bobot dan keseragaman kandungan hasil racikan dari tablet parasetamol yang dihancurkan menjadi puyer dan dibagi secara visual atau tanpa ditimbang satu persatu di beberapa apotek Kecamatan Belimbing Kota Malang menunjukkan bahwa hasil racikan puyer tidak memenuhi persyaratan keseragaman bobot dan keseragaman kandungan.

Berdasarkan hasil survey di Bandar lampung menunjukkan bahwa karena keterbatasan tenaga dan biaya, masih banyak apotek yang mempekerjakan tenaga yang tidak mempunyai kewenangan (non TTK) dalam melakukan pekerjaan kefarmasian khususnya pada proses peracikan resep.

Tenaga yang tidak sesuai kriteria tersebut maka memungkinkan proses peracikan tidak dilakukan berdasarkan teknik kefarmasian. Berdasarkan survey awal peneliti Di Apotik "X" di Bandar Lampung proses pembagian serbuk tidak sesuai tehnik kefarmasian, hal ini memungkinkan terjadinya penyimpangan bobot dan kandungan dari sediaan, selain itu membersihkan mortar hanya menggunakan serbet tanpa proses pencucian sehingga memungkinkan sisa obat racik sebelumnya tersisa di mortar dan tercampur pada obat racikan berikutnya.

Tujuan untuk memperoleh gambaran keseragaman bobot racikan sediaan serbuk bagi (pulveres) puyer kemudian dibandingkan dengan persyaratan yang ada pada Farmakope Indonesia

Sebagai bahan uji adalah hasil racikan parasetamol dalam bentuk puyer yang dikemas/dibungkus kertas berdasarkan resep dokter.

\section{Metode}

Jenis penelitian ini deskriptif dengan design Cross sectional.Tempat pengambilan sampel sediaan serbuk bagi dan kapsul yaitu di apotek Kota Bandar Lampung. Sebagai bahan uji adalah hasil racikan parasetamol dalam bentuk puyer yang dikemas/ dibungkus kertas berdasarkan resep dokter.

Pemeriksaan sampel untuk uji keseragaman bobot parasetamol dilakukan di Laboratorium Teknologi Sediaan Solida Jurusan Farmasi Politeknik Kesehatan Tanjungkarang. Waktu penelitian yaitu pada bulan Juli-Oktober 2017.

Populasi pada penelitian ini adalah seluruh apotek di Kota Bandar Lampung yaitu 
sebanyak 239 unit apotek. Pengambilan sampel dilakukan secara systematic random sampling sehingga tiap unit penelitian atau satuan elementer dari populasi memiliki kesempatan yang sama untuk dipilih sebagai sampel (Kasjono dan Yasril, 2013).

Perhitungan besar sampel yang diambil menggunakan rumus:

$$
\begin{aligned}
& n=\frac{Z_{1-\alpha / 2}{ }^{2} P(1-P) N}{d^{2}(N-1)+Z_{1-\alpha / 2}{ }^{2} P(1-P)} \\
& n=\frac{1,96^{2} \times 0,5(1-0,5) 239}{0,2^{2}(239-1)+1,96^{2} \times 0,5(1-0,5)} \\
& n=\frac{217,0504}{9,9604}=21,7913 \\
& \cong 22 \text { apotek }
\end{aligned}
$$

Sebagai obyek penelitian adalah sediaan racikan dengan resep

R/ Parasetamol $150 \mathrm{mg}$ mf pulv dtd No. XXX

\section{Hasil}

Dalam penelitian ini dilakukan pemeriksaan keseragaman bobot pada 20 bungkus sediaan serbuk bagi bentuk bungkus (puyer), yang diambil dari 22 apotek. Tetapi, pada pelaksanaannya yang dapat diperiksa hanya 21 karena sampel mengalami kebocoran kemasan sehingga tidak bisa diperiksa keseragaman bobotnya.

Uji keseragaman bobot serbuk yang dilakukan terhadap 22 apotek, dengan 20 bungkus serbuk setiap apotik didapatkan data sebagai berikut :

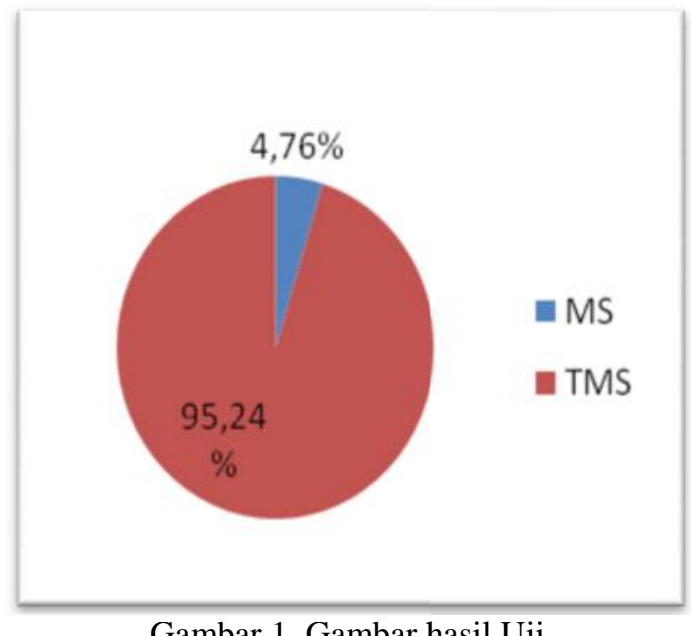

Keseragaman bobot dalam sediaan serbuk bagi bentuk bungkus (puyer) R/ Paracetamol $150 \mathrm{mg}$

\section{Pembahasan}

Dalam penelitian ini sampel diambil dari 22 apotek di Kota Bandar Lampung. Berdasarkan hasil analisa uji keseragaman bobot didapatkan dari 22 apotek hanya 1 apotek yang memenuhi keseragaman bobot serbuk bagi. Syarat keseragaman bobot sediaan tergantung dari beratnya sesuai dengan Farmakope Indonesia III, tertera untuk berat sediaan 151-300 mg maka tidak lebih dari 2 tablet yang bobotnya menyimpang lebih besar dari $7,5 \%$ dan tidak satu tablet pun yang bobotnya menyimpang $15 \%$ dari bobot rataratanya.

Sediaan serbuk bagi (pulveres) dengan $\mathrm{R} /$ parasetamol $150 \mathrm{mg}$ (puyer), mempunyai bobot tertinggi $309 \mathrm{mg}$, bobot terendah $16 \mathrm{mg}$. Bobot yang terendah ini sangat ekstrim dan terjadi pada 1 apotek diduga karena kesalahan pembacaan resep. Dimana pelaksana peracikan kemungkinan bukan tenaga yang kompeten atau bukan seorang Tenaga Tehnik kefarmasian (TTK) sehingga tidak menguasai ilmu farmasi khususnya peracikan

Hal ini dapat dijelaskan sebagai berikut : R/ Parasetamol $150 \mathrm{mg}$ mf pulv dtd No. XX mf pulv dtd No. 20 adalah singkatan dari misce fac.da tales doses yang artinya campur/buat, berilah sekian takaran sebanyak 20 bungkus sehingga pengambilannya adalah 150 dikalikan 20, sedangkan bila resep sebagai berikut :

R/ Parasetamol $150 \mathrm{mg} \mathrm{mf}$ pulv. No. XX artinya misce fac. adalah campur/buat menjadi 20 bungkus.

Kemampuan membaca dan menghitung dan meracik obat akanmempengaruhi hasil yang didapat, serta berpengaruh terhadap tercapainya efek terapi.

Variasi bobot yang lebar ini ditunjukkan dengan jumlah yang tidak sama, ada yang terlalu banyak dan ada yang terlalu sedikit. Walaupun memerlukan penelitian tersendiri namun secara logika perbedaan bobot akan mempengaruhi perbedaan kadar, Perbedaan kadar akan mempengaruhi efektifitas pengobatan terhadap penyakit. Secara psikologis perbedaan jumlah yang mencolok akan menjadikan tanda tanya pada pasien, dan menyebabkan pasien tidak yakin akan pengobatan yang sedang dijalaninya

Beberapa hal yang menyebabkan kejadian ini berdasarkan hasil pengamatan dan wawancara selama proses pengambilan adalah pembagian secara visual tanpa mengikuti langkah-langkah peracikan sediaan serbuk yang seharusnya. Pembagian secara visual 
mengindikasikan tidak samanya berat antar sediaan karena berdasarkan perkiran, namun kelemahan ini bisa dikurangi apabila langkah langkah peracikan dilakukan. Untuk membuat 20 satuan sediaan harusnya setelah digerus maka dibagi 2 bagian dengan cara ditimbang, kemudian setiap bagian dibagi 10 dengan cara visual dan bentuk mengerucut. Sebelum dilakukan pembungkusan maka diperhatikan keseimbangan satu dgn yang lain baru dilakukan pembungkusan. Pada kenyataannya setelah digerus serbuk langsung dibagi dalam 20 bagian.

Menurut Van Duin Pembagian dilakukan paling banyak 10 bungkus Apabila lebih dari 10 bungkus, maka jumlah serbuk semuanya dibagi dengan timbangan menjadi sekian bagian, hingga tiap-tiap bagian paling banyak dapat dijadikan 10 bungkus (Van Duin: 30). Menurut Anief pembagian paling banyak 20 bungkus . Apabila lebih dari 20 bungkus, maka serbuk dibagi dalam beberapa bagian dengan cara penimbangan dan tiap bagian dibagi secara visual paling banyak 20 bungkus (Anief, 2008).

Penelitian yang sejenis dilakukan Sugiyanto L, dkk, di kabupaten Klaten 2008 menunjukkan $60 \%$ sedian serbuk bagi tidak memenuhi keseragaman bobot dan kadar serta semua sediaan yang tidak memenuhi keseragaman bobot juga tidak memenuhi keseragaman kandungan. Pada Penelitian ini 95,24\% sediaan serbuk bagi (pulveres) bentuk bungkus (puyer)

Berdasarkan pembahasan di atas, maka untuk membuat sediaan serbuk bagi (pulveres) perlu diperhatikan pada proses penggerusan obat yang dilakukan secara homogen, agar zat aktif dalam serbuk bagi (pulveres) sesuai dengan resep atau sesuai dengan rentang persyaratan yang diperbolehkan.

Untuk mengurangi penyimpangan bobot yang terlalu lebar maka perlu dibuat Standar Operasional Prosedur (SOP) Peracikan. Yang memuat alur pelaksanaan dan teknis pencampuran, pembagian, pengemasan sampai dengan penyerahan obat. Menurut Van Duin apabila jumlah bungkus yang diminta pada resep termasuk banyak dan kandungan atau dosis yang diminta relatif kecil, maka sebaiknya dilakukan proses penimbangan. Apabila lebih dari 10 bungkus, maka jumlah serbuk semuanya dibagi dengan timbangan menjadi sekian bagian, hingga tiap-tiap bagian paling banyak dapat dijadikan 10 bungkus (Van Duin: 30). Apabila lebih dari 20 bungkus, maka serbuk dibagi dalam beberapa bagian dengan cara penimbangan dan tiap bagian dibagi secara visual paling banyak 20 bungkus (Anief, 2008). Hal ini dilakukan agar penyimpangan keseragaman bobot dapat diminimalisir sehingga efektivitas kerja obat hasil dari peracikan masih dapat memenuhi efek terapeutik yang diinginkan.

Simpulan hasil penelitian ini yaitu:

95,24\% keseragaman bobot parasetamol dalam resep racikan sediaan serbuk bagi (pulveres) bentuk bungkus (puyer) di apotek Kota Bandar Lampung tidak memenuhi syarat berdasarkan persyaratan dalam Farmakope Indonesia Edisi III.

\section{Daftar Pustaka}

Anief, Moh. 2008. Ilmu Meracik Obat Teori dan Praktik. Yogyakarta: Gadjah Mada University Press. 231 Halaman

Ansel, Howard C. 1989. Pengantar Bentuk Sediaan Farmasi. Jakarta: Universitas Indonesia Press. 679 Halaman

Depkes RI. 1979. Farmakope Indonesia Edisi III. Jakarta: Ditjen BPOM. 1031 Halaman.

Depkes RI. 1995. Farmakope Indonesia Edisi IV. Jakarta: Ditjen BPOM. 1290 Halaman.

Depkes RI. 2014. Peraturan Menteri Kesehatan RI Nomor: 35/ Per/ IX/ 2014 Tentang Standar Pelayanan Kefarmasian Di Apotek. Jakarta: Menteri Kesehatan RI.

Notoatmodjo, Soekidjo. 2012. Metodelogi Penelitian Kesehatan. Jakarta: Rineka Cipta. 243 Halaman

Syamsuni, H.A. 2007. Ilmu Resep. Jakarta: Buku Kedokteran EGC. 358 Halaman.

Syarif, Lalu Hidayahtullah. 2009, Kualitas Serbuk Parasetamol (Puyer) Hasil Racikan Oleh Beberapa Apotek Di Kecamatan Belimbing Kota Malang, Karya Tulis Ilmiah, Akademi Farmasi Putra Indonesia Malang, Malang.

Van, Duin. Reseptir. Untuk Siswa A.A dan Mahasiswa Farmasi. Untuk Lingkungan Sendiri. 